Doi: https://doi.org/10.17398/2340-4256.16.333

\title{
EL VALOR TEOLÓGICO DE LO BIOGRÁFICO. LA VIDA DE JOSÉ MARÍA DE LLANOS, UNA BIOGRAFÍA PASTORAL Y ESPIRITUAL
}

\author{
THE THEOLOGICAL VALUE OF THE BIOGRAPHIC. THE LIFE OF \\ JOSÉ MARÍA DE LLANOS, A PASTORAL AND SPIRITUAL BIO- \\ GRAPHY
}

JUAN ANTONIO DELGADO DE LA RosA

Madrid

Recibido: 18/11/2019 Aceptado: 22/01/2020

\section{RESUMEN}

La vida del jesuita José María de Llanos por sus peculiaridades, sus prevalencias, su contexto histórico, por su psicología, su poética, sus opciones, nos servirá para enmarcar el valor teológico de la biografía como aportación inductiva a la propia teología. Dicho de otro modo, la unión de la antropología en la teología. Ya que la condición humana, por proceder de las manos de Dios, está impregnada de las huellas de sus manos; la condición humana está llena de indicios de esa presencia de Dios. Es el alma, toda ella, la que es huella de Dios, y, por tanto, todo lo que el hombre vive, cuando lo hace a nivel suficiente de profundidad, está dando muestras de esa presencia de Dios.

Palabras clave: biografía, intrahistoria, teología, vida plena. 


\section{ABSTRACT}

The life of the Jesuit José María de Llanos for its peculiarities, its prevalence, its historical context, for its psychology, its poetics, its options, will serve to frame the theological value of biography as an inductive contribution to the theology itself. In other words, the union of anthropology in theology. Already, that the human condition, by proceeding from the hands of God, is impregnated with the traces of his hands. The human condition is full of indications of that presence of God is the soul, all of it, which is the mark of God and, therefore, everything that man lives, when he does it at a sufficient level of depth, is showing signs of that presence of God.

Keywords: biography, intrahistory, theology, full life.

\section{INTRODUCCIÓN}

La vida de José María de Llanos es una vida profunda, en la que Dios habita en el hombre y en el mundo, y mediante la cual Dios despertará a los demás en su propia profundidad, y desde esta profundidad se podrá ir descifrando el sentido misterioso del acontecimiento. El papel de la biografía está relacionado siempre con el acontecimiento, es decir, cada vida parte de un hecho o hechos significativos, que se vivencian en profundidad y se hacen parte de ese existir y revela a Dios.

Para esto, quizás necesitemos recuperar el arte de la lentitud ${ }^{1}$. Ciertamente, necesitamos reaprender y reeducarnos hic et nunc de la presencia viva de Dios y los hombres ${ }^{2}$. La sabiduría es la vida misma: la realidad del vivir, la existencia: “...no como tregua, sino como pacto conocido y aceptado en su fascinante y dolorosa totalidad. No se trata solo de vivir el instante, tarea inútil, porque la vida es duración. Lo que nos ha sido dado dura, y nosotros dentro, con y por ello"'s.

1 José Tolentino Mendonça, Pequeña teología de la lentitud (Barcelona: Fragmenta editorial, 2017), 8: "En su magnífico libro La lentitud de Milán Kundera escribe: "Cuando las cosas suceden con tal rapidez, nadie puede estar seguro de nada, de nada en absoluto, ni siquiera de sí mismo". A continuación, explica que "El grado de lentitud es directamente proporcional a la intensidad de la memoria, mientras que el grado de velocidad es directamente proporcional al del olvido".

2 Tolentino Mendonça, Pequeña teología de la lentitud, 14-16: "La vida de cada uno de nosotros no se basta a sí misma, necesitamos siempre la mirada del otro, que es mirada y que es otro, que nos mira desde otro ángulo, con otra perspectiva... Somos resultados de una cadena innumerable de encuentros, de gestos, de buenas voluntades, siembras, afectos".

3 Tolentino Mendonça, Pequeña teología de la lentitud, 38. 
Y en todo esto, descubrimos que la teología forma parte de nuestra vida, es más necesitamos una teología para la vida. No podemos marginar la teología en nuestro pensamiento y en nuestras acciones, ya que tiene un valor hondo.

Una reflexión del valor teológico de la vida concreta de una persona, es decir, su biografía, entendiendo por biografía: “...no un simple reflejo literario de la subjetividad con el propósito de conseguir con ese reflejo un símbolo interpretativo del mundo y la vida. Tal teología debe llamarse biográfica porque inscribe en la doxografía de la fe la biografía de la experiencia religiosa, de la historia personal ante el rostro velado de Dios. Es también biográfica porque no es una teología deductiva por sistema, dispuesta a mantener su carácter irrefutable, sino un relato de la historia personal ante Dios, formulado y condensado conceptualmente. La teología biográfica debe elevar el sujeto al plano de la conciencia dogmática de la teología. El sujeto, evidentemente, es la persona humana, con sus experiencia e historia en un constante proceso de identificación a partir de ellas"4.

Armonizando este binomio de intrahistoria desde el concepto unamuniano, y posteriormente orteguiano, trataba de ponernos en la definición de aprehender la esencia de las cosas (en sentido hursseliano). Así, Unamuno planteaba atender a los hechos subhistóricos; Hegel nos habla de la historia interior; y los mismos krausistas, concretamente Giner de los Ríos, hablan sobre una historia externa y una historia interna ${ }^{5}$.

Dirá Metz que la teología biográfica es mistagogía para todos, sin miedo a la vulgarización, sin temor al contacto de la vida diaria, aburrida, casi monótona, y con sus experiencias e impulsos religiosos casi indescifrables ${ }^{6}$.

Y Metz saca una clave fundamental, para atender y pararnos en realizar una biografía teológica: "En una sociedad en la que todos los modelos biográficos parecen prefabricados, diseñados de antemano, y en la que, por eso, se abate sobre las almas el desinterés por la identidad o el aburrimiento" ¿tiene cabida una biografía con valor teológico? La respuesta, evidentemente, es que sí.

Es fundamental plantear, en este mundo en el que vivimos, biografías que nos ayuden a referenciar que otro mundo es posible, si no, el ser humano se convertiría en mercancía que debe adaptarse a los distintos requerimientos

4 Johann Baptist Metz, “Teología como biografía. Una tesis y un paradigma”, Concilium, no. 115 (1976): 210 .

5 Esta reflexión está muy bien estructurada en el estudio de Ciriaco Morón Arroyo, "Unamuno y Hegel”, en Actas del IV Congreso Internacional de Hispanistas, vol. 2, coord. por Eugenio de Bustos Tovar (Salamanca: Universidad de Salamanca, 1982), 311-318.

6 Metz, "Teología como biografía. Una tesis y un paradigma”, 211. 
tecnológicos y productivos. Este sistema renuncia a diferentes dimensiones de la vida humana, que realmente son necesarias para poder tener y desarrollar una vida plena como persona, en sus aspectos esenciales, como pueden ser el sentido de la maternidad y la paternidad, el cuidado de los ancianos del hogar, la atención a la propia familia y el desarrollo de la propia vocación profesional, social, religiosa y política ${ }^{7}$.

Frente a las situaciones de desesperanza que plantea el sistema capitalista, la visión de una biografía teológica nos proyecta a una esperanza activa, donde la realidad de tipo social e histórico no es reducible a un cientificismo cerrado, en que todo está ya previsto y en que sólo puede repetirse el pasado. La realidad social e histórica y, en su base, la realidad humana, es esencialmente abierta. Hay posibilidad de novedad hacia el futuro desde el presente. La recreación de otra forma de vivirse el mundo. No es cierto que sea imposible un cambio cualitativo ${ }^{8}$. No estamos inexorablemente condenados a dar vueltas en este mundo de egoísmos y opresiones, sin posibilidad de salida. La fe humana racional es fuente de poder creador'.

El canon es la vida, no la vida elegida a capricho, sino la agobiada, la incómoda $^{10}$. Desde estas coordenadas, es casualidad que las cuestiones de la vida diaria se conviertan en problemas teológicos ${ }^{11}$.

\section{UNA BIOGRAFÍA GEOPOLÍTICA}

El valor de una biografía teológica es que se acerca a un trípode fundamental en nuestro mundo. En palabras de Walter benjamín podría ser: fe, historia y

7 Para desarrollar todos estos aspectos, puede acudirse a la esclarecedora obra de Hilario Ibáñez, De la integración a la exclusión. Los avatares del trabajo productivo a finales del siglo XX (Santander: Santander, 2002) 69-147, 158-166, 210-213, 220-240.

8 Giulio Girardi, Amor cristiano y lucha de clases (Salamanca: Sígueme 1971), 12. Esta página corresponde al prólogo que realiza José María Díez-Alegría a esta obra.

9 Girardi, Amor cristiano y lucha de clases, 13, 18, 23-24. Estas páginas corresponden al prólogo que realiza José María Díez-Alegría a esta obra: "La esperanza histórica ha de ser planteada y vivida como esfuerzo realizador de posibilidades presentes hacia el futuro. Es una actitud activa y potencial que, como tal, no se apoya en ninguna afirmación dogmática, sino en el conocimiento de la posibilidad real, en la certeza de que no es cierto que haya que renunciar a la búsqueda... el creyente tiene que ir construyendo, lo mismo que el no creyente, y con los mismos instrumentos, la perspectiva concreta de la esperanza histórica... La esperanza escatológica deja a nuestro riesgo, a nuestra responsabilidad y a nuestra búsqueda, el proyecto y la realización de la esperanza histórica, que es y tiene que ser una potencialidad creativa del hombre en el tiempo, un alumbramiento trabajoso... un cristiano genuino se hallará codo con codo con aquellos que viven el proceso histórico con esperanza creadora...".

10 Metz, "Teología como biografía. Una tesis y un paradigma", 214.

11 Metz, "Teología como biografía. Una tesis y un paradigma”, 215. 
sociedad. Si fuera desde mis planteamientos serían, recordando al viejo profesor José María Díez-Alegría, Historia, Ética y Derecho. ¿por qué plantear estos trípodes?

Ciertamente, la propia biografía de una persona, sobre todo lo que no ha cambiado $^{12}$, marca su propia teología, es decir, marca su propia experiencia en la historia de la salvación y su quehacer ético concreto. Tener presente estos trípodes, recordarlos, hacer memoria amable de ellos, es fundamentalmente un soporte y resorte vital para entender el valor teológico de una biografía. Los acontecimientos, el kairós, se manifiesta en una secuencia vivencial que desemboca en lo que Metz expresa del siguiente modo: "Crees y hablas de Dios desde ellos"13.

La biografía de José María de Llanos, cada espacio con su tiempo, marcó profundamente su trabajo, su praxis, su mentalidad, su posicionamiento. Y, especialmente, esta biografía está marcada por aquellos toques de gracia en su seguimiento de Jesucristo, con una especial sensibilidad de teodicea, en el sentido de aprehender la relación de Dios con su pueblo ${ }^{14}$.

Metz expresará esta sensibilidad de la siguiente manera: "Sensibilidad para la cuestión de Dios en relación con la historia de sufrimiento del mundo... lo que luego se llamará teología política tiene aquí sus raíces... quien hable de Dios en el sentido de Jesús asume que las propias certezas se resienten por el sufrimiento de los demás" ${ }^{15}$. Subyace en esta forma de ver la importancia y valor de una biografía una lucha e intento por transparentar públicamente la importancia que tiene el unir a Dios con el mundo. Llanos intentó, desde sus circunstancias y perplejidades, realizar un camino desde el plano del diálogo y la justicia, sobre todo en relación al encuentro cristiano-marxista. Las palabras de Metz son reveladoras al respecto: "El afrontamiento del marxismo lo entendí siempre, en realidad, como un afrontamiento de la dramatización, como crítica social, del tema de la teodicea" ${ }^{\prime 16}$.

12 Johann Baptist Metz, Dios y su tiempo. Nueva teología política (Madrid: Trotta, 2002), 235. Una lectura actual de la teología política en Desiderio Parrilla, "La polémica de la teología política y su vigencia actual", Cauriensia 14 (2019): 387-405.

13 Metz, Dios y su tiempo. Nueva teología política, 236.

14 Xavier Zubiri, El hombre y Dios, 6ª . ed. (Madrid: Alianza Editorial, 1998). Este libro, cuya primera edición es de 1984, tiene un valor especial, al ser el primero que apareció tras su fallecimiento, pues la muerte le sobrevino, casi súbitamente, mientras trabajaba en su elaboración. Leemos en su página 13: "El hombre y Dios no es la adición de dos objetos hombre y Dios, sino que es el análisis de la realidad humana en cuanto constitutivamente envuelve la versión a la realidad divina. La ' $y$ ' del hombre y Dios es una versión constitutiva experiencial... es propio de todo hombre".

15 Metz, Dios y su tiempo. Nueva teología política, 236.

16 Metz, Dios y su tiempo. Nueva teología política, 237. 
Otro hito fundamental dentro de una biografía teológica sería la de descubrir vivencias de mi yo en mis circunstancias, en esas circunstancias que quizás me salven. Llanos en 1955 hizo su segunda opción más seria. Marchó al Pozo del Tío Raimundo donde su acción pastoral, su praxis más encarnada se enfrentaría claramente con la historia misma. Metz lo expresaría del siguiente modo: "Me pregunto por qué en nuestra teología asoma y se escucha tan poco, la historia de sufrimiento de los hombres...adquieren para mí una importancia cada vez mayor las categorías supuestamente débiles de la memoria y la narración..."17.

Pero prosigamos. Otra forma de mostrar el valor de una biografía, tendría que ver con la aplicación concreta del propio Concilio Vaticano II, en la realidad geopolítica de la persona, en este caso, hablamos de un suburbio en la periferia de Madrid. Teólogos como Rahner y De Lubac siguieron partiendo de la filosofía moderna para hacer otro tipo de teología que superaba esta dicotomía tajante entre lo natural y lo sobrenatural. En definitiva, habría que afrontar la tarea de enfrentar lo que somos y lo que llevamos dentro como hombres de nuestro tiempo, mentalidad auténticamente personal y sinceridad profunda, con el contenido de la doctrina católica ${ }^{18}$. Es la teología que se impondría en el Concilio Vaticano II.

En cualquier caso, el Concilio Vaticano II legitimó la posibilidad de leer el cristianismo dentro de la perspectiva de la aplicación rigurosa del método histórico-crítico. En esta perspectiva podemos señalar el eco del Concilio Vaticano II en América Latina, mediante la difusión de comunidades de base y la formulación de la teología de la liberación ${ }^{19}$. El Concilio estaba en el corazón

17 Metz, Dios y su tiempo. Nueva teología politica, 237.

18 Karl Rahner, Peligros en el catolicismo actual (Madrid: Los libros del Monograma, 1964), 2628, 33-34, 63: "La individualidad... es un concepto que se correlaciona con lo colectivo... El hombre está constituido de tal forma que tiene que estar radicado en la materia que aísla y que particulariza, en la cual no hay ni auténtica comunidad ni auténtica individualidad... Pero el hombre es a la vez una personalidad espiritual. Esto significa que es más que un individuo, más que el caso de una ley, más que la individualización de una realidad general e idéntica. El hombre es, en verdad, auténticamente individuo, individuo uno, que es realmente único, que es irremplazable. Si es cierto que la estructura óntica de un ente representa la norma objetivamente dada de antemano de su obrar, tenemos que al deber moral del hombre pertenece también el ser y llegar a ser, por libre decisión, el individuo que es... La conciencia pertenece indudablemente a lo que hay de eterno en el hombre, a las cosas que son en cierto sentido absolutas y que representan una instancia suprema en el hombre".

19 Juan José Tamayo Acosta, Para comprender la Teología de la Liberación (Estella: Verbo Divino, 1991), 43: "Una de las grandes intuiciones del Concilio fue la atención prestada a los signos de los tiempos, es decir, a los nuevos fenómenos culturales, sociales, políticos y económicos, producidos en la gran mutación de la era moderna... La Iglesia latinoamericana estuvo atenta a esa consigna conciliar de manera escrupulosa y escrutó los signos de los tiempos y detectó uno que le parecía el más significativo y el más escandaloso: los pobres, los marginados del sistema, los sin voz, los no hombres y desde ese signo mira al mundo, relee la historia, juzga a los culpables, interpreta la realidad, reformula el mensaje cristiano 
de los cambios, de las luchas. La irrupción del binomio fe-justicia en la vida de la iglesia se produce a partir del Vaticano II. El Concilio se encontró con un mundo en el que el término justicia había adquirido una polivalencia tal que se había convertido en un concepto a repensar.

En concreto estamos ante la biografía de un publicista, de un sacerdote, de un testigo de Dios. Publicaba en distintos medios para dar a conocer un cristianismo de futuro y, por otro lado, vivía en el Pozo del Tío Raimundo en medio de la ancestral religiosidad popular de aquellos inmigrantes ${ }^{20}$. En todo ello había una dialéctica que conformaba un reto, en palabras de Metz: “...donde se enfrentaba el logos de la teología con el sufrimiento y la miseria del pueblo pobre y también con el sufrimiento de la heterogeneidad cultural..."21.

Ítem más. En esta perspectiva aparece la hondura de la esperanza gracias al contacto con las personas sencillas que revelan al Dios de los pobres como lugar teológico. La biografía adquiere brillo. Este planteamiento nos hace reflexionar desde los de abajo, lo que Metz expresa de forma clara: "Me resultó de lo más esperanzador justo donde el planteamiento era totalmente desde abajo, donde a uno se le helaba en la garganta la metafísica piadosa, donde la miseria muda le impide a uno hablar y, de entrada, lo único que cuesta es estar allí"'22.

Estas vivencias originarias de fidelidad y permanencia junto a los menos favorecidos del mundo son un elemento clave para una biografía teológica. Llanos, permaneció en estas coordenadas durante cuarenta años. Cuarenta años llenando de contenido la identidad de un pueblo que le había agarrado el corazón; construyendo comunidad, hogar en el sentido de cohabitación profunda. Esta forma de vivir cimienta una biografía de comunión, de esperanza en caridad, de una alteridad de ágape intenso, sostenido por el Creador.

Es una biografía de un testigo del evangelio encarnado, aceptando vivir una fe encarnada. Una biografía teológica que nos sitúa en el existir para los demás antes de obtener de ellos nada, o de haberse equivocado creyendo que uno iba a ser el centro y dador de todo. Dios nos precede. Tomar conciencia de ello,

y pretende transformar la vida. La Iglesia de América Latina lleva hasta el final esa nueva orientación humanista y comienza por constatar la contradicción existente entre las declaraciones de principios a favor de la persona y la negación real de la dignidad humana de los pobres, tal como se produce en el Tercer Mundo... La única traducción que admite la centralidad del hombre es la centralidad de los pobres...".

20 Anticipa así la importancia de la religión como factor de integración que se vive en la situación actual. Miguel Osorio García de Oteyza, "El factor religioso en la integración de los inmigrantes en España", Cauriensia 14 (2019): 605-617.

21 Metz, Dios y su tiempo. Nueva teología política, 238.

22 Metz, Dios y su tiempo. Nueva teología política, 238. 
entender esta conciencia como acto puro, configura al testigo en su biografía. Somos aprendices ante Dios y ante los hombres ${ }^{23}$.

Nos transforma esta forma de ser la biografía teológica porque no entramos en el pecado de alejar de nosotros el sufrimiento, la vida, las heridas, las alegrías, los gozos, las cicatrices de los demás. Llanos mantuvo viva con su biografía original y personalísima la narración en pos de Jesucristo, atendiendo al mandato de cuidar a los más pequeños. Esta memoria viva hoy la recogemos como referencia colectivizante para todos los hombres de buena voluntad, para su Iglesia, para creyentes y no creyentes. Metz lo expresaba de forma magistral del siguiente modo: "Esta sensibilidad para el dolor ajeno, esta atención al sufrimiento de los demás, en la propia acción, constituye el centro de esa nueva forma de vivir que se relaciona con Jesús" ${ }^{24}$.

Aquellos toques de gracias que experimento José María de Llanos en su biografía lo colocan en una obediencia hacia el Siervo, al que confía su persona, su vida, su historia e intrahistoria. Es una obediencia sutil que conforma su conciencia. Metz hablará de esta autoridad desde la clave de los que sufren: "La autoridad de los que sufren es la única en la que se manifiesta la autoridad del dios que juzga a todos los hombres del mundo. En su obediencia consiste la conciencia moral; y lo que llamamos la voz de ésta no es sino nuestra reacción a la llamada del sufrimiento ajeno"25.

Desde estas reflexiones, podemos dilucidar que la teología no se haya al margen de estas experiencias biográficas, sino que entra de lleno en la memoria de los mismos testigos de Dios ${ }^{26}$. En esta línea apunto una idea de Metz que me parece clave: "En el proceso teológico es ya imprescindible la referencia al sujeto y la contextualización" $"$.

José María de Llanos tuvo de telón de fondo una contextualización difícil en todas sus vertientes, en una época marcada por la inexistencia de democracia en España. Pero, por encima de todo, la confesión de fe en el Dios trinitario y en el marco de todo, una justicia indivisa, semejante a lo que expresa Metz: “...que abarque a todos, para vivos y muertos, para los sufrimientos del presente y del pasado, por eso, la fe cristiana tiene siempre ese componente de dejarse llevar por el interés en una justicia indivisa; en este sentido es a la vez mística y política: mística porque no ceja en el interés por la salvación de los sufrimientos

23 Metz, Dios y su tiempo. Nueva teología política, 234.

24 Metz, Dios y su tiempo. Nueva teología politica, 227.

25 Metz, Dios y su tiempo. Nueva teología política, 230.

26 Conferencia Episcopal Española, Testigos del Dios Vivo. Reflexión sobre la misión e identidad de la Iglesia en nuestra Sociedad (Madrid: EDICE, 1985).

27 Metz, Dios y su tiempo. Nueva teología política, 142. 
del pasado por expiar; y política, porque su interés por una justicia completa la obliga constantemente, también, a buscar justicia entre los vivos. El logos de la teología va acompañado de ese interés o, mejor, de esta visión"28.

Este modo de hacer historia desde una singular intrahistoria forma parte del discurso sobre Dios y este ejercicio ayuda e implementa a la teología un contenido netamente humano, lo que Metz concretará así: "El logos de la teología se caracteriza por una mentalidad histórica..." ${ }^{29}$. Por eso, en una biografía teológica los más vulnerables: “....son el banco de prueba de la justeza y autenticidad de nuestro lenguaje teológico... es la mística de ojos abiertos"30.

Esta línea de profundización en el valor teológico de una biografía nos trae el propio credo del padre Llanos. Un credo asentado en la historia concreta, una historia donde hay filias y fobias. Un credo que pregunta a Dios: “¿a qué viniste, Señor?" Un credo que es anamnesis universal para el mundo de hoy, en el este sentido en el que Metz recuerda: "El teólogo que no quiera engañarse ni a si a los demás, el que haga teología... como intento siempre nuevo de discurso sobre Dios, está y estará obligado siempre a la universalidad... Dios no es propiedad privada de la Iglesia o de la teología" 31 .

Creo sinceramente que así lo experimento José María de Llanos. Y desde aquí, aparece el sentido de la biografía teológica en su vertiente práctica. Esto nos pone inexorablemente en el valor del testimonio, vivencial y pastoral.

\section{UNA BIOGRAFÍA QUE PARTE DEL DASEIN ${ }^{32}$}

Heidegger en 1933 escribía una carta a Elisabeth Blochmann donde expresaba que la situación del momento requería una gran dosis de acción, compromiso y participación en la construcción de un mundo fundado en el pueblo y que solamente se podía asumir este reto si nos exponíamos a nosotros mismos y tomábamos posesión de esta construcción de una manera nueva ${ }^{33}$. Esta idea es

28 Metz, Dios y su tiempo. Nueva teología política, 143.

29 Metz, Dios y su tiempo. Nueva teología política, 144.

30 Metz, Dios y su tiempo. Nueva teología política, 144.

31 Metz, Dios y su tiempo. Nueva teología política, 176.

32 Martin Heidegger (1889-1976), filósofo alemán, concibe al ser humano en relación esencial con las cosas y con el mundo, bajo el nombre de dasein.

33 Martin Heidegger, Naturaleza, Historia, Estado, edición y traducción de Jesús Adrián escudero (Madrid: Trotta, 2018), 9. 
brillante. El destino de cada individuo está estrechamente interconectado con el destino del pueblo ${ }^{34}$.

Este espacio es un espacio vital. Para Heidegger tiene mucha importancia la cuestión del espacio. Para él, el espacio es: "un complejo de lugares al que

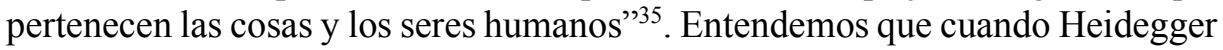
habla de espacio piensa sobre todo en un espacio entendido en términos existenciarios. Es un espacio pragmático, público y significativo que remite al ámbito de la acción en el que se desarrolla las actividades de la vida humana. Se trata, en definitiva, de un espacio vital ${ }^{36}$.

Estos elementos resultan fundamentales para entender el valor teológico de una biografía. El espacio vital determina la esencia del sujeto, de alguna manera va a influir sobre su sentido de pertenencia ${ }^{37}$. José María de Llanos vivió esta realidad de forma consecuente. El pueblo le "mordió" como relataba él en infinidad de ocasiones y desde entonces, aun sabiendo, que no pertenecía al mismo, quiso encarnar su biografía en aquel Pozo del Tío Raimundo. Lugar que es historia que para Heidegger significará el suceder en su totalidad. El suceder de lo que sucedió ${ }^{38}$. Pero solamente podemos aprehender la esencia de la historia desde el horizonte del tiempo ${ }^{39}$ y en él el ser humano es consciente de su ser y del ser de otros entes. El ser humano tiene conciencia. Esta conciencia es una capacidad fundamental de su existencia. El ser humano se inquieta por su propio ser, y gracias a la conciencia puede preocuparse por é ${ }^{40}$.

El estar en el mundo del dasein, en virtud de su facticidad: "se ha dispersado y hasta fragmentado en formas del estar-en. La multiplicidad de estas formas puede ponerse de manifiesto, mediante la siguiente enumeración: habérselas con algo, producir, cultivar y cuidar...esas maneras de estar-en tienen el modo de ser del ocuparse..." ${ }^{\prime 4}$. Realmente, relacionarse con el mundo es posible porque el dasein, en cuanto estar-en-el-mundo, es como es.

Esta perspectiva, nos centra en lo nuclear de esta realidad del dasein: "Si estar en el mundo es una constitución fundamental del dasein en la que éste se mueve no sólo en general, sino especialmente en el modo de la cotidianidad,

34 Heidegger, Naturaleza, Historia, Estado, 12.

35 Heidegger, Naturaleza, Historia, Estado, 14.

36 Heidegger, Naturaleza, Historia, Estado, 15.

37 Heidegger, Naturaleza, Historia, Estado, 16.

38 Heidegger, Naturaleza, Historia, Estado, 45.

39 Heidegger, Naturaleza, Historia, Estado, 48.

40 Heidegger, Naturaleza, Historia, Estado, 76.

41 Martin Heidegger, Ser y tiempo, traducción, prólogo y notas de Jorge Eduardo Rivera (Madrid: Trotta, 2003), 83. 
entonces ese estar-en-el-mundo deberá ser experimentado ya desde siempre de una manera óntica" ${ }^{42}$. Un dasein que en el conocimiento tiene una forma de existir que fundamenta el estar en el mundo: "Ésa es la razón por la cual el estaren-el-mundo reclama, en tanto que constitución fundamental, una previa interpretación" ${ }^{3}$.

El dasein existe. El dasein es, además, el ente que soy cada vez yo mismo. $\mathrm{Al}$ dasein existente le pertenece el ser-cada-vez-mío como condición de posibilidad de la propiedad e impropiedad ${ }^{44}$. Así lo vivió Llanos en su existir cotidiano, entrando de lleno en lo concreto de la realidad: "El análisis de la mundaneidad del mundo tuvo constantemente ante la mirada el fenómeno del estar-en-elmundo en su totalidad, sin que por ello se destacaran todos sus momentos constitutivos con la misma claridad fenoménica que el fenómeno del mundo mismo. La interpretación ontológica del mundo partió del análisis del ente intramundano porque el dasein en su cotidianidad, que sigue siendo en todo momento nuestro punto de vista, no sólo está de un modo general en un mundo, sino que corrientemente se comporta en relación al mundo de un modo particular: inmediata y regularmente, el dasein está absorbido por su mundo... ¿quién es el dasein en la cotidianidad? Todas las estructuras de ser del dasein y, por ende, también el fenómeno que responde a la pregunta por el quién, son modalidades de su ser. $\mathrm{Su}$ carácter ontológico es existencial" ${ }^{\text {45 }}$.

José María de Llanos estuvo viviendo esta existencia plenamente en medio de los otros. El existir con los otros. Este "con" tiene el modo de ser del dasein, sería algo así como: "como un estar-en-el-mundo ocupándose circunspectivamente de él... el mundo es desde siempre el que yo comparto con los otros..."46.

Resulta significativo que, cuando tratamos del valor teológico de una biografia, sea tan importante estas formulaciones del dasein, que proyectan la biografía de un ser humano, que está a su vez proyectado a un compromiso con una causa: la de Llanos fue la del Pozo del Tío Raimundo. Causa que se decide desde la existencia (dasein) expresamente asumida: "Sólo esta auténtica solidaridad hace posible un tal sentido de las cosas" ${ }^{\prime 47}$.

Nos parece relevante tener en cuenta todo esto. José María de Llanos vivió este compromiso encarnatorio desde la perplejidad. Le sobrevenía esta forma de estar en el mundo. Llanos aprehendía la realidad en una actitud vital reflexiva

42 Heidegger, Ser y tiempo, 86.

43 Heidegger, Ser y tiempo, 88-89.

44 Heidegger, Ser y tiempo, 79.

45 Heidegger, Ser y tiempo, 139.

46 Heidegger, Ser y tiempo, 143-144.

47 Heidegger, Ser y tiempo, 147. 
de su propio interior hacia una intelección de su propio carácter, unas veces en una visión positiva, otras veces en una aptitud bien negativa: "La disposición afectiva es un modo existencial fundamental de la aperturidad cooriginaria del mundo, la coexistencia y la existencia, ya que esta misma es esencialmente un estar-en-el-mundo" ${ }^{48}$.

Esta historia biográfica tiene este valor. Un valor teológico-filosófico en este sentido profundo fenomenológico. Lo que tiene una historia está dentro del contexto heraclitiano del devenir, por tanto, tiene historia y hace historia, por tanto, lógicamente determinó desde su presente siempre pasado un futuro: "Historia significa un encadenamiento de sucesos y de efectos que se extiende a lo largo del pasado, presente y futuro... historia es el específico acontecer en el tiempo del dasein existente, de tal manera que se considera como historia en sentido eminente el acontecer ya pasado y a la vez transmitido y siempre actuante en el convivir"49.

Podemos, argumentar desde estas coordenadas la vida del jesuita Llanos, ya que estaba realmente conectado y relacionado como sujeto, de los aconteceres que se iban sucediendo en su propia biografía.

Ítem más, podemos preguntarnos: ¿afectará entonces el acontecer de la historia a la conexión de sujeto y objeto $?^{50}$ Para nosotros la respuesta más evidente es poner una mirada en su giro intencional sobre su biografía como valor esencial. Es mantener el elemento de la encarnación, en un sentido de suyo, en vías de profundidad. Llanos salió de sí mismo en éxtasis hacia el mundo. Ascenso y descenso se unen en una dynamis que robustece una indigencia finita para dignificarla como creatura hechura de Dios en la fuerza binómica de la encarnación y la kénosis. Dios es fecundo en el interior del ser humano. Su espíritu está en cada célula, en cada rincón psíquico u orgánico porque es un espíritu "asumente" que vivifica por doquier. Este ser humano es transcendentalmente un espíritu somatizado, definido en su contorno existencial finito por el ser Absoluto que es divina presencia que nos hace gran bien abriéndonos a su infinitud y esto nos hace portadores de una finitud especial, es decir, nos constituye la más absoluta vivencia originaria que el Creador portador de la radicalidad infinita: la del amor en comunión.

50 Heidegger, Ser y tiempo, 403. 
Estamos en una etapa donde la posverdad se nos anuncia como dogma de vida y necesitamos figuras como las de José María de Llanos, para entrar en profundidad en todas las dimensiones que tenemos los seres humanos.

Aquí aparece el effeta, la apertura al encuentro, la salida de uno mismo. En este sentido, escribía Fernando Rielo: "Es más bien un diálogo de amor puro con el absoluto: un modelo dialogal que proporciona la dirección y el sentido a nuestra comunicación con el prójimo, $\mathrm{y}$, en definitiva, a nuestra relación con la naturaleza, las cosas, la sociedad, la cultura, la historia..." 51 .

Todo esto nos aleja de la cosificación ${ }^{52}$ desde cualquier ángulo. Esta realidad nos revierte en la estructura abierta del ser persona. No estamos encerrados en nosotros mismos. Si adquirimos la categoría de persona "es por la divina presencia constitutiva del sujeto absoluto en su espíritu. Somos personas por ser definidos por la divina presencia constitutiva de las personas divinas en nuestro espíritu creado. Esta divina presencia constitutiva es de carácter hereditario que hace de la persona humana mística deidad de la divina deidad. Reside en este carácter hereditario la constitución filial del ser humano en relación con Dios..." $" 53$. Esta realidad va a configurar nuestro modus vivendi y operandi "La divina presencia constitutiva es lo que viene impuesto en nuestro actuar, nuestro pensar, nuestro querer, nuestro sentir..."

Ítem más. Dado que yo, yo que vivo, no me traído a mí mismo a la vida: “este viviente, este sí y esta carne sólo vienen a sí efectivamente en el proceso de la Vida absoluta que viene a sí en su Verbo, experimentándose en él, que se experimenta en ella, en la interioridad fenomenológica recíproca que es su espíritu común. De esta manera, el dios trinitario del cristianismo es el Dios real que vive en cada Sí viviente, sin el que ningún viviente viviría, el que cada viviente testimonia en su condición misma de viviente" 55 .

Ciertamente, el Verbo de Dios nos va a permitir comprender, la relación original que se establece entre todos los hombres y la propia experiencial "del otro" en su posibilidad última: "El Verbo es la condición en la que todo Sí carnal

51 Fernando Rielo Pardal, Mis meditaciones desde el modelo genético (Madrid: Fundación Fernando Rielo, 2001), 17.

52 Ramón Valls Plana, Del yo al nosotros. Lectura de la fenomenología del espíritu de Hegel, (Barcelona: Estela, 1971), 111-147: "Hegel nos va a describir la primera experiencia de intersubjetividad. Se trata de la dialéctica del señor y el siervo. En ella, la relación intersubjetiva se encuentra lastrada todavía por la relación de la autoconciencia con la naturaleza y a causa de ella va a ocurrir una cosificación del sujeto opuesto. En estas condiciones no podrá conseguirse todavía la realización del concepto de espíritu porque no podrá darse la independencia perfecta de los sujetos...".

53 Rielo Pardal, Mis meditaciones desde el modelo genético, 102.

54 Rielo Pardal, Mis meditaciones desde el modelo genético, 103.

55 Michel Henry, Encarnación. Una filosofia de la carne (Salamanca: Sígueme, 2001), 224. 
viviente viene y puede venir a sí...La vida absoluta revela ser aquí, en su verbo, el acceso fenomenológico al otro Sí...."56.

José María de Llanos, se unió a la humanidad del pueblo en esta concepción de la encarnación, entendiendo que la vida es en el Verbo como manera de unirnos los hombres: "Es ese prius que hace posible a su vez toda forma de relación histórica, transhistórica o eterna entre ellos" ${ }^{" 57}$.

\section{UNA BIOGRAFÍA TEOLÓGICA PRÁCTICA}

La vida cristiana de un creyente y la reflexión teológica inherente a la fe dan lugar a dos funciones distintas y necesarias, pero mutuamente relacionadas: la función pastoral y la función teológica: La función pastoral equivale a la acción eclesial del pueblo de Dios en el mundo. La función teológica consiste en reflexionar sobre las manifestaciones e intervenciones de Dios en la humanidad a través de Jesucristo por medio de la Iglesia. Realmente, antes de pensar se es y antes que haya una teología cristiana hay una vida eclesial de creyente. Y, por otra parte, la operación reflexiva produce un conocimiento teológico, al que puede preceder una acción o acto pastoral.

Se trata de ver con claridad, que este aspecto, incorpora luz a una biografía con valor teológico. El sacerdote fundante del cooperativismo en España (Mondragón), José María de Arizmendiarrieta ${ }^{58}$, lo expresaba con su lema: Mundum labor mutat, "el trabajo cambia el mundo" 59 .

56 Henry, Encarnación. Una filosofia de la carne, 320.

57 Henry, Encarnación. Una filosofía de la carne, 321.

58 José María Arizmendiarrieta, Pensamientos, $2^{\mathrm{a}}$. ed. (Mondragón: Otalora, 2007), 13: "Este cura estima que no está fuera de su campo en este terreno de realidades humanas cuando lo que hace es un nuevo espíritu de justicia y de amor".

59 Hay una experiencia de empresa cooperativa actualmente en España que hunde sus raíces en los inicios del cooperativismo en el pueblo de Mondragón (Arrasate), con la cooperativa "Mondragón Corporación". Destacamos brevemente algunos datos sobre esta realidad que aporta una alternativa posible a la manera que tiene el capitalismo hoy día de entender las relaciones entre el propietario de los medios de producción y el trabajador, es decir, el sistema neoliberal que estamos desarrollando denigra al trabajador haciéndole una pieza irrelevante dentro de la estructura económica. En cambio, el sistema cooperativo plantea igualdad en las decisiones y en la responsabilidad del funcionamiento de la empresa cooperativa. Es un hito histórico que un sacerdote, asentara las bases sólidas de un proyecto que es alternativa en la España de finales de los años 50. Esta realidad nace concretamente en 1959 con el sacerdote José María de Arizmendiarrieta, que propone la idea de crear una entidad financiera que promueva la captación de ahorro popular y que canalice recursos hacia el desarrollo cooperativo. En este mismo año y tras una larga reflexión se crea el Lagun-Aro con objeto de resolver el problema creado a los cooperativistas al negarles el gobierno el derecho a afiliarse al régimen general de la Seguridad Social, aludiendo a su condición de propietarios en contraposición a la de ser trabajador por cuenta ajena. Lagum-Aro se desarrolló no sólo para cubrir una necesidad económica sino también fue una 
Esta realidad es una praxis histórica. Se trata de transformar el mundo injusto en el Reino de la justicia de Dios. En esta línea estaba José María de Llanos. La justica en esta tierra. Sería una forma de actualizar la praxis de Jesucristo. Praxis de solidaridad con los pobres: "de cara a la justicia del reino de Dios y de obediencia al dios del reino"60.

Nos parece nuclear esta perspectiva para recalcar el aspecto teándrico, divino-humano o cristológico que posee la acción pastoral. El propio proceso de salvación necesita, requiere y exige la cooperación de Dios y del hombre: “...de ahí que la teología pastoral se base en la cristología y escatología cristianas"61.

Jesucristo no dejó ni creo un modelo rígido de acción. El mismo se entregó para liberar. La demanda, entonces, nace de esta génesis: "Lo que Jesús demanda a sus discípulos son actos y acciones que prolonguen su praxis en actitud de fe compartida y de conversión verificada"62.

Esta biografía teológica corresponde al marco de la misión testimonial, indagando el sentido cristiano de la vida en los acontecimientos de la existencia, preocupándose de poner de relieve los valores de la persona y su transcendencia: "Es, en definitiva, una teología pastoral de la existencia humana, personalmente considerada, dentro de una concepción comunitaria. Dicho de otro modo: Es una

\footnotetext{
Escuela de aprendizaje al poder gestionar los propios trabajadores prestaciones y cuotas sirviendo para desarrollar en las ciudades y en el mundo rural un gran sentido de responsabilidad y realismo. En 1962 se construye un nuevo edificio denominado Eskola Politeknikoa que acoge a más de mil alumnos en las especialidades de mecánica, electricidad, electrónica, fundición, delineación y automatismos. Éste centro es reconocido oficialmente en 1969 como Escuela de Ingeniería Técnica Industrial. Ligado también a la formación se crea en 1966 la Cooperativa ALECOP (Actividad laboral escolar cooperativa) como instrumento para propiciar en la práctica el principio de igualdad de oportunidades, compatibilizando trabajo y estudio a los alumnos que se incorporan a este proyecto. Todo este original proyecto que nace de hacer frente a una maquinaria pesada como es el capitalismo, para ser alternativa solidaria. El cooperativismo plantea una forma de ser empresa diferente a la tradicional, donde la persona es considerada eje central, siendo el capital tan sólo instrumento de desarrollo, lo que viene a significar que en las cooperativas la decisión no depende del capital sino de las personas, donde una persona realmente equivale a un voto decisorio. Son por ello empresas de personas y no de capital. No se van del territorio donde realizan su actividad y tienen una relación respetuosa con las personas y con el entorno, por ello son pioneras en el desarrollo de la responsabilidad social. Por último, dejar apuntando que es muy valiosa la experiencia emprendedora de Carlos de la Higuera, impulsor de la economía social en la Comunidad de Madrid, con los colegios Gredos San Diego como referente dentro de las cooperativas de enseñanza. Interesante ver estos planteamientos a la luz del texto: José María Díez-Alegría, "En torno al problema de la cogestión obrera", Revista Hispanoamericana Razón y Fe, 144, nº. 644-645 (1951): 210-220.

60 Casiano Floristán Samanes, Teología Práctica. Teoría y praxis de la acción pastoral (Salamanca: Sígueme, 1991), 140-141.

61 Floristán Samanes, Teología Práctica. Teoría y praxis de la acción pastoral, 142.

62 Floristán Samanes, Teología Práctica. Teoría y praxis de la acción pastoral, 142.
} 
hermenéutica de la vida teologal, en clave eclesiológica, con un talante humanista y existencialista" ${ }^{63}$.

La conciencia de José María de Llanos le llevo a este "cruzar el puente" y actuar de una forma práxica que sirvió para realizar procesos de diversa índole, transformadores más allá del propio barrio del Pozo del Tío Raimundo: "La praxis equivale a una actuación única, capaz de mover en un solo proceso la totalidad del hombre y del mundo. La praxis sería el acto del hombre total produciendo efectos totales, en todas las áreas al mismo tiempo"64. El cristiano verdaderamente es quien practica el amor en la medida en que el amor cambia las relaciones sociales mediante acciones y praxis realmente humanas: "En definitiva, es el que actúa según la praxis de Jesús" ${ }^{\circ 5}$.

Llanos trabajó por hacer inteligible el contenido de la fe cristiana y también, por dirigir y suscitar la praxis cristiana como praxis irrenunciable a la esperanza en caridad, es decir, de salvación y liberación en el mundo ${ }^{66}$. Dicho de otra manera, la ortodoxia se cumple en la ortopraxis ${ }^{67}$. Así lo atestiguamos en la vivencia y actuación del jesuita José María de Llanos. En este sentido, Pannenberg afirma que: "La referencia a la praxis de la vida no constituye sólo una disciplina teológica particular, sino que abarca a toda la teología en su totalidad"68.

63 Floristán Samanes, Teología Práctica. Teoría y praxis de la acción pastoral, 155.

64 José Comblin, "De la acción cristiana”, Vispera, $n^{\circ} .7$ (1973): 22: “...cristiano es el que practica o hace...".

65 Floristán Samanes, Teología Práctica. Teoría y praxis de la acción pastoral, 186.

66 Juan Alfaro Jiménez, "Problemática actual del método teológico en Europa", en Liberación y cautiverio. Debates en torno al método de la teología en América Latina, ed. por Enrique Ruiz Maldonado, (México DF, 1975), 426-428: "Evidentemente, si la fe y la teología se reducen a meras interpretaciones, no interesan o interesan poco. Es necesario presentarlas en relación con el compromiso de liberación".

67 José María Díez-Alegría "Éticas y moral cristiana", en Evangelio e Iglesia. XVI Congreso de Teología (Madrid: Centro Evangelio y Liberación, 1996), 216: "Lo más paradigmático de la contribución cristiana debería ser el testimonio práctico de una identificación visceral con la causa de los pobres. También la verificación efectiva de que el amor al prójimo como a sí mismo, también a los enemigos, es raíz de una moralidad plena y de una manera muy especial hace patente con su actitud y con sus actuaciones lo que es estar libres de la esclavitud del dinero y de la codicia...". También cabe valorar muy positivamente el siguiente artículo, José María Díez-Alegría, "Iglesia y utopía (dificultades eclesiales en la Utopía)", en la obra conjunta De la fe a la utopía social (Santander y Barcelona: Sal Terrae y Cristianisme i Justícia, 1970), 47: "El teólogo alemán N. Greinacher cree necesaria la elaboración de una teología profética en Europa, que tome plenamente en serio el desafío de la teología de la liberación... El español J. I. González Faus propone una teología que no renuncie a la historia de la libertad y a la Ilustración, pero siendo consciente, a su vez, de la dialéctica que ésta comporta: es decir, que sepa responder lúcida y críticamente a los desafíos provenientes de la razón ilustrada y posilustrada, asumiendo sus conquistas, pero descubriendo sus límites y reduccionismos: un progreso que es, en buena medida, contrario a la igualdad, una razón que no tiene en cuenta la fraternidad...". Cf. Esteban Anchústegui "La fraternidad y la doctrina social de la iglesia: persona, caridad y justicia social", Cauriensia 14 (2019): 151-188. 431.

68 Wolfhan Pannenberg, Teoría de la ciencia y teología (Madrid: Ediciones Cristiandad, 1981), 
Podemos decir, por tanto, que José María de Llanos, en esta biografía teológica, nos acerca al misterio de Dios; "Cada uno determina personalmente el sentido y el destino de su propia vida en una relación de dependencia con lo que realmente aparece como valor universal" 69 . Llanos marca un camino de resolución de problemas: "El problema de fondo está relacionado con la cuestión de cómo un acontecimiento histórico particular puede tener significado universal para todos los hombres... Si esto es posible, parece necesaria una determinada mediación histórica".

Llanos hizo de su biografía un trabajo de transparentar quién era Dios y quién era el hombre. Llanos estuvo para ello en permanente búsqueda: "Ser hombre para los demás es una tarea grabada en la estructura de nuestra condición humana",70.

La historia de la vida de José María de Llanos, su biografía, se convierte en una “... suerte de mistagogía, en una guía hacia el misterio de Dios. Las biografías de las existencias teológicas son la continuación de la biografía-raíz, la biografía de Jesús de Nazaret"71. De aquí nace la necesidad de una teología que siga el carácter movedizo de la existencia que en definitiva se puede traducir como enraizarse más en Jesucristo: "La teología deviene experiencial allí donde reconquista la dimensión del testimonio biográfico y piensa partiendo del seguimiento" 72 .

\section{EL VALOR TEOLÓGICO DE LA BIOGRAFÍA DE JOSÉ MARÍA DE LLANOS, DESDE MI PROPIA EXPERIENCIA COMO CAUCE PARA CO- NOCER LA REALIDAD}

José María de Llanos y José María Díez-Alegría son dos jesuitas que han aportado mucho a la historia de España. Los dos estuvieron en el Pozo del Tío Raimundo 37 años de su vida. A los dos los conocí y les he dedicado parte de mis estudios. Estuvieron en el Pozo del Tío Raimundo desde 1955. Allí, no solamente ocuparon el espacio, sino que se preocuparon de conocerlo, vivenciarlo, amarlo....

69 Edward Schillebeeckx, Jesús. La historia de un viviente, (Madrid: Ediciones Cristiandad, 1981), 568.

70 Schillebeeckx, Jesús. La historia de un viviente, 571.

71 Michael Schneider, Teología como biografia. Una fundamentación dogmática (Bilbao: Desclée de Brouwer, 2000), 30.

72 Schneider, Teología como biografía. Una fundamentación dogmática, 96-97. 
Desde estas coordenados, me gustaría explicar mi experiencia con ellos, para, desde ella, significar que sus vidas fueron vitales y con un valor humano, pastoral y espiritual muy fuerte.

Me centraré en Llanos. Estando en Portugal, recibió la correspondencia más dura de toda su vida, en la que se le comunicaba la muerte de sus hermanos. Esto, unido a su enfermedad crónica intestinal (su dolor de estrellas), le marcaría indeleblemente toda su vida, teniendo un carácter recio y una tendencia muy fuerte a expresar su fracaso.

Nació en un barrio de Madrid de clase alta, lo tenía todo bien establecido y enmarcado en aquellos tiempos de juegos y atrevimiento, le faltaban tres meses para acabar la carrera de Químicas... Pero todo cambió con el primer toque de gracia subiendo una escalera. Siempre he pensado que era una idea magnífica lo de subir hacia arriba para encontrar o encontrarse. Y así le sucedió. Ese toque de la gracia le predispuso para entrar en contacto con los jesuitas y realizar posteriormente su adhesión a la Compañía. Pero hay que decir que nunca fue un jesuita al uso, siempre marcó una diferencia con su modo de vivir y de actuar. Esto validaría, posteriormente, que su biografía merezca la pena elevarla al constructo teológico.

Muchas veces me han preguntado qué les diría el papa Francisco a estos jesuitas atípicos, al provenir él mismo de la Compañía.

El imperativo de conciencia era transmitirnos que habían vivido, cómo lo habían vivido. Son nuestros indicadores de caminos. El Llanos que exponemos es un jesuita en permanente perplejidad, pero, que indudablemente nos remite permanentemente al Dios de la vida. Toda experiencia auténtica de verdad busca por sí misma su expansión ${ }^{73}$, su ser conocida y reconocida. Expresará el papa Francisco que comunicando el bien, éste se arraiga y se desarrolla.

José María de Llanos nos proyecta a vivificar una memoria que podríamos llamar, memoria amable de la vida, o como expresa el papa Francisco: “...podríamos llamar deuteronómica" ${ }^{\text {" }}$.

Estudié a Llanos desde la perspectiva del profetismo, lo que me ha ayudado a repensar y darle un valor teológico a su biografía de cara a seguir creciendo en la teología práctica. Llanos ya hemos comentado que se sintió fracasado muchas veces, pensó y comunicó que no había evangelizado, pero la realidad es bien distinta como. No podemos negar, que se encontró con una inmigración

73 Papa Francisco, Exhortación Apostólica Evangelii Gaudium (Ciudad del Vaticano: Libreria Editrice Vaticana, 2013), $\mathrm{n}^{\circ} .9$.

74 Papa Francisco, Exhortación Apostólica Evangelii Gaudium, nº 13. 
interior con unas formas de religiosidad popular alejadas del Concilio Vaticano II. Pero, paradójicamente, acabó siendo uno más, aunque relativamente, nunca se consideró un sacerdote obrero, fue un jesuita, y con un fondo burgués cuitado. Celebraba su eucaristía muchas veces solo, queriendo estar con el Señor en el pan y el vino de forma recogida y en ellas presentaba a todos los hombres. Después rezaba el rosario, y más tarde, protegía a los miembros de Comisiones Obreras de la policía. De la misma manera que, a los hombres que construían su casita por la noche para que no se la pudiesen derribar, los iluminaba con su linterna.

Llanos quería permanentemente incluir a los pobres en la sociedad, para lo cual cruzó un puente que en aquella época era poco usual y dio consistencia a su misión, una misión que como recuerda el Papa Francisco: "De nuestra fe en Cristo hecho pobre, y siempre cercano a los pobres y excluidos, brota la preocupación por el desarrollo integral de los más abandonados de la sociedad"75.

Llanos siempre entendió como eje central para su estar en la vida la justicia como elemento esencial. Él lo denominaría una justica en la esperanza de una caridad encarnada en medio de los pobres. Este lugar teológico, sin duda para él, estaba precedido del trabajo que Pedro Arrupe estaba haciendo en la Compañía de Jesús con su giro copernicano, para entablar un diálogo sincero de cómo la misión jesuítica estaba cimentada en la opción por los más pobres. Creo, sinceramente, que el papa Francisco comparte esta concepción antropológica del ser cristiano: "El corazón de Dios tiene un sitio preferencial para los pobres, tanto que hasta él mismo se hizo pobre. Todo el camino de nuestra redención está signado por los pobres..."

Más aún. Esto me recuerda aquello que Llanos siempre comentaba del texto de los Hechos de los Apóstoles, cuando un pobre solicitaba limosna en la puerta del templo. Siempre comentaba que el templo era bello porque el pobre estaba allí. Era un modo de percibir el valor estético a través de tantos hombres y mujeres que caravaneaban por este mundo de la marginalidad. Éste Llanos es el de la frontera. El papa Francisco continúa en esta línea: "Todos los cristianos estamos llamados a cuidar a los más frágiles de la tierra" ${ }^{77}$.

Y Llanos, lo realizaría a través de una paz que tuviera en cuenta, el crecimiento y progreso de los más desfavorecidos. Esto es nuclear en Llanos, en

75 Papa Francisco, Exhortación Apostólica Evangelii Gaudium, nº 186.

76 Papa Francisco, Exhortación Apostólica Evangelii Gaudium, no $\mathrm{n}^{\circ} .97$.

77 Papa Francisco, Exhortación Apostólica Evangelii Gaudium, nº 209. 
Díez-Alegría. Una paz que buscase el bien común. El ser ciudadanos del mundo desde el respeto a los derechos fundamentales.

Los hombres tienen un fin temporal y eterno, pero ambos se funden en una sola y dulce palabra: pax. Todas las cosas aspiran a la paz, y ésta es la tranquilidad del orden: pax omnium rerum tranquillitas ordinis. Como reposo y tranquilidad del ser en todas sus manifestaciones... el anhelo y tendencia universal a la paz se puede considerar como el más hondo substrato de la Historia ${ }^{78}$.

José María de Llanos, podemos afirmar, siguiendo la exhortación apostólica del papa Francisco, que fue un evangelizador con espíritu, es decir, que se abrió sin temor a la acción del espíritu Santo, padre amoroso del pobre ${ }^{79}$. Comenta Francisco también que es muy sano acordarse de los primeros cristianos y de tantos hermanos a lo largo de la historia ${ }^{80}$ que estuvieron cargados de parresia, de audacia y coraje. Fueron incansables fundadores de proyectos que anticiparon, como el grano de mostaza el Reino de Dios: "Tenemos un tesoro de vida y de amor que es lo que no puede engañar, el mensaje que no puede manipular ni desilusionar... Es la verdad que no pasa de moda porque es capaz de penetrar allí donde nada

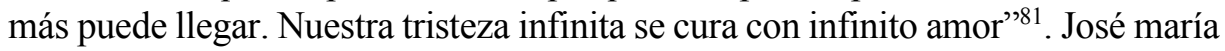
de Llanos sostuvo estas convicciones con su propia experiencia. Estuvo junto a su pueblo desde su éxodo al Pozo del Tío Raimundo. Llevó allí la alegría de la Buena Nueva, así lo expresaba el Papa Francisco: "Jesús quiere que toquemos la miseria humana, que toquemos la carne sufriente de los demás" $\$ 2$.

Las cuestiones que aquí recorremos, a través, de la experiencia que el doctorando ha tenido en el encuentro con estos dos jesuitas, parte de un recuerdo entrañable de ambos. Los dos optaron, con sus dudas de fe, en el seguimiento de Jesucristo en sus caminos y elecciones, dirá el Papa Francisco: "La fe nos abre el camino y acompaña nuestros pasos a lo largo de la historia" $"$.

José María de Llanos se encarnó, fue tocado por la gracia de Dios. Trasmitió que Dios era algo muy grande y vivo, invitando al mundo a comprenderlo. Un Dios amor. La vida es la esencia, la materia primordial de toda manifestación originaria. Toda impresión acontece en la vida. Dirá Michel Henry que: "El dato

78 Agustín de Hipona, "El anhelo de la paz", en Obras de San Agustín, tomo I (Madrid: Biblioteca de Autores Cristianos, 1957), 246.

79 Papa Francisco, Exhortación Apostólica Evangelii Gaudium, nº 259.

80 Papa Francisco, Exhortación Apostólica Evangelii Gaudium, $\mathrm{n}^{\circ} .263$.

81 Papa Francisco, Exhortación Apostólica Evangelii Gaudium, $\mathrm{n}^{\circ} .265$.

82 Papa Francisco, Exhortación Apostólica Evangelii Gaudium, nº 270.

83 Papa Francisco, Carta Encíclica Lumen Fidei (Ciudad del Vaticano: Librería Editrice Vaticana, 2013), $n^{\circ} .8$. 
es originariamente una afección de la vida" ${ }^{84}$. Desde estas coordenadas, asociamos la vida del hombre, su biografía intrahistórica, a la vida de Dios en una perfecta unión y comunión de amor.

\section{REFERENCIAS BIBLIOGRÁFICAS}

Anchústegui, Esteban. "La fraternidad y la doctrina social de la iglesia: persona, caridad y justicia social”. Cauriensia 14 (2019): 151-188.

Floristán Sesmanes, Casiano. Teología Práctica. Teoría y praxis de la acción pastoral. Salamanca: Salamanca, 1991.

Osorio García de Oteyza, Miguel. "El factor religioso en la integración de los inmigrantes en España”. Cauriensia 14 (2019): 605-617

Girardi, Giulio. Amor cristiano y lucha de clases. Salamanca: Sígueme, 1971.

Heidegger, Martin. Naturaleza, Historia, Estado. Edición y traducción de Jesús Adrián Escudero. Madrid: Trotta, 2018.

Henry, Michel. Encarnación. Una filosofia en la carne. Salamanca: Sígueme, 2001.

Henry, Michel. La fenomenología radical, la cuestión de Dios y el problema del mal. Madrid: Ediciones Encuentro, 2013.

Metz, Johann Baptist. Dios y su tiempo. Nueva teología política. Madrid: Trotta, 2002.

Pannenberg, Wolfhann. Teoría de la ciencia y teología. Madrid: Ediciones Cristiandad, 1981.

Rahner, Karl. Peligros en el catolicismo actual. Madrid: Los libros del Monograma, 1964.

Rielo Pardal, Fernando. Mis meditaciones desde el modelo genético. Madrid: Fundación Fernando Rielo, 2001.

Schillebeeckx, Edward. Jesús. La historia de un viviente. Madrid: Ediciones Cristiandad, 1981.

Schneider, Michael. Teología como biografía. Una fundamentación dogmática. Bilbao: Desclée de Brouwer, 2000.

Tamayo Acosta, Juan José. Para comprender la Teología de la Liberación. Estella: Verbo Divino, 1991.

Tolentino Mendonça, José. Pequeña teología de la lentitud. Barcelona: Fragmenta, 2017.

84 Michel Henry, La fenomenología radical, la cuestión de Dios y el problema del mal (Madrid: Ediciones Encuentro, 2013), 12-13. 
Valls Plana, Ramón. Del yo al nosotros. Lectura de la fenomenología del espíritu de Hegel. Barcelona: Estela, 1971.

Zubiri, Xavier. El hombre y Dios. Madrid: Alianza Editorial, 1998.

Juan Antonio Delgado de la Rosa

Camino de Turrubuelo 44, dúplex 7 40500 Riaza, Segovia (España) 